\title{
Intraocular lens power calculation following laser refractive surgery
}

\author{
Christopher Hodge ${ }^{1,2^{*}}$, Colm McAlinden ${ }^{3,4}$, Michael Lawless ${ }^{1,2}$, Colin Chan ${ }^{1,5}$, Gerard Sutton ${ }^{1,2}$ and Aifric Martin ${ }^{1,6}$
}

\begin{abstract}
Refractive outcomes following cataract surgery in patients that have previously undergone laser refractive surgery have traditionally been underwhelming. This is related to several key issues including the preoperative assessment (keratometry) and intraocular lens power calculations. Peer-reviewed literature is overwhelmed by the influx of methodology to manipulate the corneal or intraocular lens (IOL) powers following refractive surgery. This would suggest that the optimal derivative formula has yet been introduced. This review discusses the problems facing surgeons approaching IOL calculations in these post-refractive laser patients, the existing formulae and programs to address these concerns. Prior published outcomes will be reviewed.
\end{abstract}

Keywords: Cataract, Laser refractive surgery, Intraocular lens calculations

\section{Introduction}

The unfortunate irony for post laser refractive surgery patients has been the difficulty in achieving consistent, accurate refractive outcomes following cataract removal and intraocular lens (IOL) implantation [1,2]. Subsequently, researchers have described various errors in IOL calculation and developed a variety of approaches to overcome the reported refractive surprises [3-5]. Although refractive results have improved significantly over time, it would appear an optimal solution remains elusive, indicated by the significant number of methods available to aid post refractive IOL calculations [6]. The purpose of this review is to identify the issues relating to IOL power calculations and describe the available methods to improve the accuracy of post cataract surgery outcomes. Published results will be discussed to provide an overview of current outcomes.

\section{Review}

There are three main sources of error in IOL calculation for patients who have previously undergone laser refractive surgery: the index of refraction error, the measurement of corneal radius error and the inherent errors within the IOL formulas [7]. These are discussed in more detail below.

\footnotetext{
* Correspondence: christopher.hodge@visioneyeinstitute.com.au

${ }^{1}$ Vision Eye Institute, Level 3270 Avenue Chatwood, Victoria, NSW, Australia

${ }^{2}$ Save Sight Institute, University of Sydney, Sydney, NSW, Australia

Full list of author information is available at the end of the article
}

\section{Keratometry-derived errors}

Most keratometers measure the central anterior surface of the cornea only. The production of an accurate corneal power value thereby is reliant on several assumptions; firstly that the corneal surface has uniform curvature and power; and secondly that the relationship between the anterior and posterior surfaces remains fixed. The use of the average keratometric index, routinely 1.3375 , assumes that these models are adhered to. Ablative laser procedures inherently change the relationship between the anterior and posterior curvature of the cornea, immediately invalidating the above assumptions. Furthermore, the true index of refraction will vary dependent on the amount of laser ablation (and remaining tissue) further impeding the use of a basic or standardized keratometric index [8]. In eyes that have undergone myopic ablative refractive procedures, the resulting keratometry readings obtained by standard keratometry or topography will appear erroneously high, subsequently leading to an underestimation of the final IOL power [1]. Depending on the literature, this value is estimated to represent a difference of between 14\% to $25 \%$ [9]. The opposite will occur in patients that were previously hyperopic.

This error may be mediated by adjusting the corneal power values through the use of refraction-derived keratometry values or through the use of regression-based formulas $[10,11]$. Although current literature provides adequate outcomes, the results do remain variable suggesting further 
validation is still required [12-15]. Bypassing the keratometric index and calculating corneal power by using Gaussian optics formula or ray tracing, based on Snell's law, may yet provide the optimal approach [12]. Both approaches require the examiner to obtain valid measurements for anterior and posterior corneal curvatures.

A further functional error may occur in obtaining the actual keratometric measurement [7]. Corneal curvature measurements not obtained from the corneal centre may be erroneous [16]. This error has been referred to as the "radius error". This may reflect both the incapability of some keratometry units (or corneal topographers) to measure the central corneal area and the inability of these devices to incorporate the change to an aspherical cornea produced by the surgery $[17,18]$. These errors have been ameliorated with the use of diagnostic technology such as ray tracing and with the evolution of lasers using larger effective optical zones. The radius error impacts all post refractive IOL patients, however the risk of significant invalid measurements is increased in patients with small or decentered laser ablations.

It has been suggested that the magnitude of error in IOL power calculations is much lower in previously hyperopic eyes than in post myopic eyes due to the relatively minimal corneal steepening in hyperopic laser in situ keratomileusis (LASIK) and a diminished reduction in the change of refraction index secondary to the corneal steepening $[19,20]$.

\section{IOL calculation formulas}

Most third and fourth generation theoretical formulas share the same basic approach. This includes the primary equation to determine the effective lens position (ELP), based on parameters such as keratometry and axial length. Thereafter, this result is used in the original vergence formula to determine the suggested IOL power [21-23]. Identified by Aramberri, the use of the post laser keratometry values to determine the ELP is flawed [3]. Essentially, anterior chamber depth should not change as a result of the laser surgery. Therefore, using the artificially lower keratometry values will lead to an underestimation of the ELP and resulting IOL power. The proposed "Double-K" procedure, using the preoperative keratometry for the ELP equation and the postoperative keratometry values in the IOL power calculation was derived to overcome this. Subsequently the "Double-K" technique figures in the majority of the calculations proposed [24,25]. This issue was similarly recognized by Holladay and is incorporated into his proprietary software available to surgeons (by checking the "previous RK" box on the IOL Consultant Program) [4]. Of note, within the Holladay IOL Consultant Program, if the pre-laser keratometry values are unknown, a standard value is then used, which has been variably reported as 43.86 and 44.00 in the literature $[4,26]$. The true value remains under proprietary considerations.

The Haigis- $\mathrm{L}$ formula represents an alternative approach to bypass the inherent errors of post refractive subjects. The formula applies a correction curve to the existing measurement to derive the effective corneal power thereby bypassing both keratometer and radius errors [16]. This value is then incorporated into the original Haigis formula for standard eyes. Significantly, the original formula does not use corneal radius as a predictor of IOL position thus further reducing the risk of the formula error.

\section{Post-refractive surgery derivative formula}

To fully describe the historical outcomes of post refractive IOL power formulas, a PubMed database search was performed for relevant literature between 1998 to October 2014. The search included the following keywords; IOL power calculation, refractive surgery, keratometry, LASIK, photorefractive keratectomy (PRK) and radial keratotomy (RK). Two hundred and twenty four articles were retrieved and evaluated. Approximately 70 keratometry or IOL power formulas were found. These were separated into 4 separate sub-headings including history methods, change in manifest refraction, no prior data and others (Table 1). The majority of calculations included in the "Others" column include topography derived keratometry values. Some approaches may have differed minimally from other established formulas and may not have been included.

A discussion of the main formulas and respective refractive outcomes follows.

\section{Methods based on the knowledge of patient clinical history (refraction and keratometry)}

Originally proposed independently by Eiferman and Holladay, the "clinical history method" represented the first method to overcome the intrinsic IOL calculation issues in post laser refractive surgery patients $[27,28]$. For many years, this method remained the so-called "gold standard" for comparison [29]. The methodology remains relatively simple. The effective keratometry value is calculated by subtracting the change in refraction induced by the treatment from the preoperative mean corneal power. This method effectively bypasses the index of refraction error. The main disadvantage of the clinical history method and similar formulas is the reliance on preoperative keratometry and refractive data. The effectiveness of these methods may be reduced by the possibility of further errors including but not limited to: the use of inaccurate central corneal measurements, variation in measurement units before and after surgery and the potential impact of index myopia $[7,9,30]$. Practically, the follow-up required to obtain the data may be particularly cumbersome if the patient had their refractive surgery elsewhere or a number of years previously. In a large study, Wang et al. found that 
Table 1 List of known post laser refractive formulas

\begin{tabular}{|c|c|c|c|}
\hline $\begin{array}{l}\text { History methods (plus change } \\
\text { in manifest refraction) }\end{array}$ & $\begin{array}{l}\text { Change in manifest } \\
\text { refraction methods }\end{array}$ & No prior data & Others \\
\hline Camellin*[31]\# & Adjusted ACCP $[62]^{\circ}$ & Actual K $(a+p)[59]$ & CAS-OCT \\
\hline Clinical History [27] \# & $\begin{array}{l}\text { Adjusted Atlas } 9000 \\
\left(4 \mathrm{~mm} \text { Zone) }[34]^{\circ}\right.\end{array}$ & Awwad [61] & Consensus-K [63] \\
\hline Corneal Bypass $[42]^{\circ}$ & Adjusted Atlas Ring Values $[45]^{\circ}$ & BESSt [55]\# & Double $-K^{\wedge}[3]$ \\
\hline Feiz-Mannis $[64]^{\circ} \#$ & Adjusted EffRP $[35]^{\circ}$ & Canovas Ray Tracing- Aberration [65] & Corneal topography \\
\hline Jarade Index of Refraction*[1 1]\# & Barrett True-K [66] & Ferrara [67]\# & Adjusted Flat K \\
\hline \multirow[t]{21}{*}{ Seitz-Speicher*[31] } & Camellin-Calossi [31] & Feiz Myopic [64] & Atlas 0-3 \\
\hline & Chokshi SE [37] & Feiz Hyperopic [64] & Galliei Sim K \\
\hline & Diehl-Miller [38] & Haigis-L $[68]^{\circ} \#$ & Orbscan Flat Axis \\
\hline & Diehl-Date-Miller [39] & Hamed [35] & Orbscan Mean and Total Mean Power \\
\hline & Khalil Regression [40] & Hard Contact Lens [69]\# & $\begin{array}{l}\text { Orbscan } 1.5 \mathrm{~mm}, 2.00 \mathrm{~mm} \text { and } 2.50 \mathrm{~mm} \\
\text { Mean Power }\end{array}$ \\
\hline & Latkany [41]\# & lanchulev [46]\# & Orbscan 4.0 mm Total Optical Power \\
\hline & Masket $[36]^{\circ} \#$ & Galilei $[70]^{\circ}$ & Orbscan 5.0 mm Total Axial Power \\
\hline & Modified Masket $[71]^{\circ}$ & Geggel Ratio [60] & Pentacam True Net Power (TNP) \\
\hline & Rosa [72] & Kim [47] & Pentacam Central TNP \\
\hline & Srivannaboon & Leccisotti [49] & Pentacam 4.5 mm Equiv $\mathrm{K}$ \\
\hline & Stakheev and Balashevich [73] & Mackool [48]\# & ORange Intraoperative Wavefront [52] \\
\hline & Walter [42]\# & Maloney [34]\# & Ray Tracing (OKULIX Software) [74] \\
\hline & & Maloney-Koch-Wang [34] ${ }^{\circ}$ & \\
\hline & & Razmjoo Regression [75] & \\
\hline & & Ronje [76]\# & \\
\hline & & Saiki (A-P) [77] & \\
\hline & & Saiki (C-P) [56] & \\
\hline & & Seitz-Speicher-Savini [31] & \\
\hline & & Savini-Barboni-Zannini [78]\# & \\
\hline & & Shammas $[44]^{\circ}$ & \\
\hline & & Wang [34] & \\
\hline
\end{tabular}

$\wedge$ Used in conjunction with other methods to derive IOL power.

* May be used without clinical history information.

Incorporated into the American Society of Cataract \& Refractive Surgeons Post Refractive Calculator.

\#Available in the Hoffer-Savini LASIK IOL Power Tool.

Note: references not provided for IOL formulas based on topographic measurement variations.

formulas requiring both the preoperative refraction and keratometry values performed poorly compared to other available methods. Results showed significant variability with high IOL prediction errors and relatively low percentages of outcomes within $\pm 0.5 \mathrm{D}$ and $\pm 1.0 \mathrm{D}$ [29]. This has been mirrored in subsequent studies and these methods should no longer be used [31-33].

\section{Methods based on the knowledge of change in manifest refraction}

Several approaches aim to bypass the need for preoperative keratometry and represent valid alternatives.

A number of methods propose applying a correction, based on the change in refraction, to the postoperative keratometry value. This value is then appropriately inserted into the Double-K formula to provide the final IOL power [34,35]. The "Adjusted Effective Refractive Power (EffRP)" and "Adjusted Atlas 9000 (4 mm Zone)" methods are commonly used examples available through the American Society of Cataract and Refractive Surgeons (ASCRS) IOL Calculator. These methods rely on the availability of the particular topographical unit and require the examiner to directly assess the measurement to confirm the quality of the reading.

Masket and Masket recognized the difficulty in obtaining accurate postoperative corneal measurements and effectively bypassed these potential errors by creating a formula based on the change in laser correction [36]. The 
authors determined that the chief corrective factor in post-refractive patients was the amount of pre-ablative myopia. Subsequently, a value based on a simple regression formula deriving the change in manifest refraction, was added to the standard IOL calculation. Other authors have undertaken similar approaches with basic variations of the regression formulas [37-41]. Walter et al. described an even simpler approach: by assuming the patient never had myopic laser surgery and replacing the standard IOL target with the pre-laser amount of myopia [42]. Although the authors reported excellent results, the initial study has been criticized by the use of a small sample size to derive the formula.

The risk of index myopia related errors remains considerable for methods based on the change in manifest refraction.

\section{Methods based on no prior data}

Common to all previous formulas is the requirement for preoperative keratometry and/or refraction data. This is often unavailable to surgeons and alternative approaches therefore remain necessary. Formulas based on postoperative information serve either to re-measure or recalculate the current keratometry values prior to entry into existing IOL calculations.

The over-refraction of a hard contact lens has been described previously $[30,43]$. This effectively re-measures the corneal curvature rather than providing a recalculated value. This approach has been limited by technical and time constraints. Difficulty in achieving an adequate refraction in patients with poor visual acuity further reduces the effectiveness of this method.

Shammas et al. previously described a simple equation modifying post-laser keratometry values to determine the corrected corneal power to be used in IOL calculation formulas [44]. Other researchers have taken similar approaches. The Maloney and Koch-Maloney methods convert the post-laser keratometry values from corneal topography to the exact power present at the anterior corneal surface and then add an average negative power value for the posterior corneal surface [45]. These latter formulas have been based on values obtained by the Atlas topography (Zeiss, Germany) and thereby remain of limited value to practices without this unit.

As described earlier, the Haigis-L formula bypasses the various errors through the use of a correction formula then applied to the standard Haigis formula. The relative availability of the Haigis-L formula across several platforms including both instrument and web-based programs, has led to the formula rapidly becoming a focus of many comparative studies albeit with varying results $[46,47]$.

Mackool et al. suggested an alternative approach [48]. The cataract is first removed and the patient is required to wait for an hour before an aphakic refraction is undertaken. An algorithm is then applied to the refraction to determine the true IOL power to be inserted. Ianchulev and Leccisotti also described "on the table" approaches with reasonable postoperative outcomes [49,50]. Sheppard, however, compared all three intraoperative aphakic formulae with mixed results [51]. The author suggested that intrinsic differences within the formulae determine the most appropriate use in patients, that is, both the Leccisotti and Ianchulev formulae appear to provide better results for posterior IOL positions and the Mackool algorithm more appropriate for anterior chamber IOLs. Intraoperative reforming of the anterior chamber either with balanced salt solution or visco-surgical devices and variable refractive indexes remain significant obstacles for these methods achieving consistent postoperative outcomes [49-51]. More recently, the use of intraoperative wavefront aberrometry has been described to further refine outcomes [52]. Results using the WaveTec Intraoperative Wavefront aberrometer were compared with several established formulae in post refractive patients. The Wave $T$ ec readings were more accurate than predictive formulae, most often predicting to within $\pm 0.5 \mathrm{D}$ of emmetropia. Tellingly however in this study, no method was able to achieve this accuracy more than $50 \%$ of the time, which highlights the relative inaccuracy of the post refractive formulae. Ianchulev and co-authors recently described more optimistic results with intraoperative aberrometry. They detailed results achieved with the Optiwave Refractive Analysis (ORA) System wavefront aberrometer that appeared to surpass those with comparative preoperative methods of IOL calculation [46].

\section{Ray tracing}

The principles of ray tracing suggest that using this method for IOL calculations may provide more accurate, reproducible results compared to existing alternate keratometric methods. Ray tracing technology is currently available in many topographical systems although results may be enhanced with the addition of external computational programs such as Okulix (Oculix, Dortmund, Germany). Savini et al. indicate that ray-tracing avoids the systemic issues involved with post refractive cases [53]. Calculating the refracted ray at both anterior and posterior surface avoids the use of the average, fictitious corneal refractive index. The ability of the ray tracing software to be performed over any corneal diameter minimizes potential instrument and thereby radius error. Finally, formula errors are avoided as the IOL position may be calculated without respect to the single anterior curvature value [53]. Hoffmann et al. suggested that although the prediction accuracy of ray tracing remains only comparable to third-generation formulae, the accuracy in abnormal eyes, those with long or short axial length and those with prior refractive surgery is improved [54]. The results 
Table 2 Published post refractive IOL calculation outcomes within $\pm 0.5 \mathrm{D}$ and $\pm 1.0 \mathrm{D}$ of target

\begin{tabular}{|c|c|c|c|c|}
\hline First author (Year) & Method & Percentage within $\pm 0.50 \mathrm{D}$ & Percentage within $\pm 1.00 \mathrm{D}$ & $\begin{array}{l}\text { Number of patients } \\
\text { assessed overall }\end{array}$ \\
\hline Savini (2013) [12] & Overall & $60.7 \%$ & $85.7 \%$ & 28 \\
\hline DeMill et al. (2011) [25] & Ocular MD Calculator Average & $76 \%$ & $90 \%$ & 21 \\
\hline Hamed (2002) [35] & EffRP Adjusted & $70 \%$ & $94 \%$ & 100 \\
\hline Date et al.(2013) [39] & Diehl-Miller-Date Formula & $49 \%$ & $93 \%$ & 23 \\
\hline Masket (2006) [36] & Masket & $93.3 \%$ & $100 \%$ & 30 \\
\hline $\mathrm{Hu}(2010)[59]$ & Actual K $(a+p)$ & $80 \%$ & $100 \%$ & 10 \\
\hline lanchulev (2014) [46] & Intraoperative Refractive Biometry & $67 \%$ & $94 \%$ & 246 \\
\hline \multirow[t]{2}{*}{ Geggel (2013) [60] } & Geggel Ratio /Haigis & $78 \%$ & $100 \%$ & 34 \\
\hline & Consensus & $70 \%$ & $93 \%$ & \\
\hline Saiki (2013) [77] & Anterior-Posterior Method & $46.4 \%$ & $75 \%$ & 28 \\
\hline Saiki (2013) [56] & Central-Peripheral Method & $48 \%$ & $68 \%$ & 25 \\
\hline Saiki (2014) [74] & Ray Tracing & $41.7 \%$ & $75 \%$ & 24 \\
\hline Savini (2014) [53] & Ray Tracing & $71.4 \%$ & $85.7 \%$ & 21 \\
\hline Canto et al. (2013) [52] & ORange & $39 \%$ & $60 \%$ & 53 \\
\hline Yang (2013) [24] & Best Performing & $58 \%$ & $90 \%$ & 62 \\
\hline Wang et al.(2010) [29] & Best Performing & $67 \%$ & $90 \%$ & 72 \\
\hline McCarthy et al.(2011) [32] & Best Performing & $58.8 \%$ & $84.3 \%$ & 173 \\
\hline Tang (2010) [33] & OCT Guided & $78 \%$ & - & 27 \\
\hline Arce (2009) [79] & Orbscan Central 2 mm TMP & $53 \%$ & $78 \%$ & 77 \\
\hline Qazi (2007) [80] & Orbscan 4 mm TOP & $80.9 \%$ & $95.2 \%$ & 21 (back calculated) \\
\hline Shammas (2007) [81] & Shammas & - & $93.3 \%$ & 15 \\
\hline Javadi (2012) [82] & Adjusted Flat K 3 mm & $44.4 \%$ & $61.1 \%$ & 18 \\
\hline Cai (2011) [83] & Orbscan Mean Power & $48.4 \%$ & $80.6 \%$ & 62 \\
\hline
\end{tabular}

obtained by Savinni and co-authors in recent papers further highlights the potential of using values based on ray tracing principles $[12,17,53]$.

\section{Available sources of calculations}

Although a number of formulae may now provide improved refractive outcomes in post laser refractive surgery patients, it remains a difficult and time-consuming action to derive the IOL powers using multiple formulae. This task however, has been made significantly easier with the advent of several available web- or app-based programs.

Developed with the support of the ASCRS, the ASCRS Post Refractive Calculator (www.iolcalc.org) remains an efficient method for obtaining multiple IOL formulae. The program utilizes several referenced formulas and provides an average of all available methods. Recognizing the increasing reliance on non-historical methods, the website recently introduced a further value representing the average of all non-historical methods. The formulae from the ASCRS website have been used in several studies and appear to provide consistent, reliable outcomes $[24,25,29,52]$.
The Hoffer-Savini LASIK IOL Power Tool represents a similar approach, albeit through the use of a downloadable spreadsheet (available from www.iolpowerclub.org/ post-surgical-iol-calc). The user enters the available keratometry and biometric values from which the spreadsheet provides the recalculated corneal power values to use in subsequent IOL formulae. The spreadsheet also calculates the IOL power directly through several available formulae. Although the IOL Power Tool replicates some of the formulae in use with the ASCRS web tool, the use of alternative formulae may provide further information for the surgeon.

Several other websites or applications remain available albeit without the range of the aforementioned sites. The Asia Pacific Association of Cataract and Refractive Surgeons (www.apacrs.org) provides the Barrett True-K formula for post-refractive IOL patients. The McCarthy Post Refractive IOL Calculator (www.mccarthyeye.com/ post-refractive-iol-calculator) provides several relevant formulae based on the outcomes of the authors' prior study of 173 post-LASIK eyes [32]. Several applications are available for use with existing iOS or Android devices. These include the Eye Pro application, which utilizes the 
BESSt post refractive IOL formula and the PAK post refractive IOL formula. [Note: the BESSt formula requires the input of keratometry values obtained by the Pentacam topography unit (Oculus Pentacam, Germany) [55-57]].

\section{Results}

Within the UK National Health Service, figures of within $\pm 0.50 \mathrm{D}$ for $55 \%$ and within $\pm 1.00 \mathrm{D}$ for $85 \%$ have been used to provide a standard for refractive outcomes following cataract surgery in normal eyes [58]. While this gauge underestimates the visual outcomes now expected, it supplies a benchmark standard that has been used in previous studies [29,32,39]. Table 2 delineates comparative results from past papers evaluating a variety of formulas in post laser vision correction cataract procedures.

The range for values occurring within $\pm 0.50 \mathrm{D}$ and \pm $1.00 \mathrm{D}$ remains highly variable. The lowest percentage is reported by Canto et al. [52] at 39\% and 60\% respectively, for their small series detailing the use of an intraoperative wavefront aberrometer. This would suggest that recording the simple intraoperative value does not take into account the impact of all surgical variables. Conversely, Masket and Masket reported $93.3 \%$ and $100 \%$ of patients within \pm $0.50 \mathrm{D}$ and $\pm 1.00 \mathrm{D}$ respectively of the intended correction [36]. Both Geggel and Hu similarly reported $100 \%$ of their patients within $\pm 1.00 \mathrm{D}$ following surgeries in their respective cohorts [59,60]. Although Masket and Masket's original paper was based on a relatively small sample size, which may have biased the final outcome, importantly the success of the formula has replicated with consistently good outcomes in further studies [31,32,61].

A criticism of most post-refractive IOL formulae remains the relatively low numbers used to derive the accompanying outcomes. The range amongst the listed publications remains significant from a minimum of 10 patients to a maximum of 246 (median of 27 patients) [46,59]. The availability of formulae and relative number of post refractive patients proceeding to surgery would suggest that further audits might provide additional important information to assist surgeons in choosing the most appropriate formulae. Similarly, it might provide a platform for a revised methodology.

\section{Conclusion}

The optimal correction of post-refractive IOL patients represents an ongoing concern for surgeons. The use of available programs and existing formulas serves to improve upon prior results however literature suggests that consistent outcomes similar to those obtained in virgin eyes currently remains out of reach. The continued audit of post-refractive IOL outcomes, the development of corneal imaging technology, and improved intraoperative wavefront aberrometry may provide the best opportunity for surgeons in the short to medium term.

\section{Competing interests}

The authors declare that they have no competing interests.

\section{Authors' contributions}

All authors participated in the design of the review and helped. All authors read and approved the final manuscript.

\section{Author details}

${ }^{1}$ Vision Eye Institute, Level 3270 Avenue Chatwood, Victoria, NSW, Australia. ${ }^{2}$ Save Sight Institute, University of Sydney, Sydney, NSW, Australia. ${ }^{3}$ Flinders University, Bedford Park, Adelaide, South Australia, Australia. ${ }^{4}$ Wenzhou Medical College, Wenzhou, Zhejiang, China. ${ }^{5}$ School of Optometry and Vision Science, University of New South Wales, Sydney, Australia. ${ }^{6}$ University College Dublin, Montrose, Dublin, Ireland.

Received: 19 November 2014 Accepted: 11 March 2015

Published online: 02 April 2015

\section{References}

1. Seitz B, Langenbucher A, Nguyen NX, Kus MM, Kuchle M. Underestimation of intraocular lens power for cataract surgery after myopic photorefractive keratectomy. Ophthalmology. 1999;106:693-702.

2. Kalski RS, Danjoux JP, Fraenkel GE, Lawless MA, Rogers C. Intraocular lens power calculation for cataract surgery after photorefractive keratectomy for high myopia. J Refract Surg. 1997;13:362-6.

3. Aramberri J. Intraocular lens power calculation after corneal refractive surgery: double-K method. J Cataract Refract Surg. 2003;29:2063-8.

4. Koch DD, Wang L. Calculating IOL power in eyes that have had refractive surgery. J Cataract Refract Surg. 2003;29:2039-42.

5. Abdelghany A, Alio JL. Surgical options for correction of refractive error following cataract surgery. Eye and Vision. 2014;1:2.

6. Skiadaresi E, McAlinden C, Pesudovs K, Polizzi S, Khadka J, Ravalico G. Subjective quality of vision before and after cataract surgery. Arch Ophthalmol. 2012;130:1377-82.

7. Chan CC, Hodge C, Lawless M. Calculation of intraocular lens power after corneal refractive surgery. Clin Experiment Ophthalmol. 2006;34:640-4.

8. McAlinden C. Corneal refractive surgery: past to present. Clin Exp Optom. 2012;95:386-98.

9. Koch DD Gimbel H, Lawless M. Cataract surgery following refractive surgery. Cataract surgery following refractive surgery Focal Points, clinical modules for ophthalmologists. AAO, vol. 19. 2001. p. 1-13.

10. Savini G, Barboni P, Zanini M. Correlation between attempted correction and keratometric refractive index of the cornea after myopic excimer laser surgery. J Refract Surg. 2007;23:461-6.

11. Jarade EF, Abi Nader FC, Tabbara KF. Intraocular lens power calculation following LASIK: determination of the new effective index of refraction. J Refract Surg. 2006;22:75-80.

12. Savini G, Hoffer KJ, Carbonelli M, Barboni P. Scheimpflug analysis of corneal power changes after myopic excimer laser surgery. J Cataract Refract Surg. 2013;39:605-10.

13. Tang M, Li Y, Avila M, Huang D. Measuring total corneal power before and after laser in situ keratomileusis with high-speed optical coherence tomography. J Cataract Refract Surg. 2006:32:1843-50.

14. Srivannaboon S, Reinstein DZ, Sutton HF, Holland SP. Accuracy of Orbscan total optical power maps in detecting refractive change after myopic laser in situ keratomileusis. J Cataract Refract Surg. 1999;25:1596-9.

15. Sónego-Krone S, López-Moreno G, Beaujon-Balbi OV, Arce CG, Schor P, Campos M. A direct method to measure the power of the central cornea after myopic laser in situ keratomileusis. Arch Ophthalmol. 2004;122:159-66.

16. Haigis W. Challenges and approaches in modern biometry and IOL calculation. Saudi J Ophthalmol. 2012;26(1):7-12.

17. Savini G, Calossi A, Camellin M, Carones F, Fantozzi M, Hoffer KJ. Corneal ray tracing versus simulated keratometry for estimating corneal power changes after excimer laser surgery. J Cataract Refract Surg. 2014;40:1109-15.

18. Rabsilber TM, Reuland AJ, Holzer MP, Auffarth GU. Intraocular lens power calculation using ray tracing following excimer laser surgery. Eye. 2007;21:697-701. 
19. Seitz B, Langenbucher A. Intraocular lens calculations status after corneal refractive surgery. Curr Opin Ophthalmol. 2000;11:35-46.

20. Langenbucher A, Haigis W, Seitz B. Difficult lens power calculations. Curr Opin Ophthalmol. 2004;15:1-9.

21. Holladay JT, Prager TC, Chandler TY, Musgrove KH, Lewis JW, Ruiz RS. A three-part system for refining intraocular lens power calculations. J Cataract Refract Surg. 1988;14:17-24.

22. Retzlaff JA, Sanders DR, Kraff MC. Development of the SRK/T intraocular lens implant power calculation formula. J Cataract Refract Surg. 1990;16:333-40.

23. Hoffer KJ. The Hoffer Q formula: a comparison of theoretic and regression formulas. J Cataract Refract Surg. 1993;19:700-12.

24. Yang R, Yeh A, George MR, Rahman M, Boerman H, Wang M. Comparison of intraocular lens power calculation methods after myopic laser refractive surgery without previous refractive surgery data. J Cataract Refract Surg. 2013;39:1327-35

25. Demill DL, Moshirfar M, Neuffer MC, Hsu M, Sikder S. A comparison of the American Society of Cataract and Refractive Surgery post-myopic LASI K/PRK intraocular lens (IOL) calculator and the Ocular MD IOL calculator. Clin Ophthalmol. 2011;5:1409-14.

26. Kohnen T, Koch DD. Cataract and Refractive Surgery. 2nd ed. Berlin Heidelberg: Springer; 2006.

27. Holladay JT. Consultations in refractive surgery. Refract Corneal Surg. 1989;5:203.

28. Eiferman RA. Corneal wound healing and the future of refractive surgery. Refract Corneal Surg. 1989;5:73-4

29. Wang $L$, Hill WE, Koch DD. Evaluation of intraocular lens power prediction methods using the American Society of Cataract and Refractive Surgeons Post-Keratorefractive Intraocular Lens Power Calculator. J Cataract Refract Surg. 2010;36:1466-73

30. Cua IY, Qazi MA, Lee SF, Pepose JS. Intraocular lens calculations in patients with corneal scarring and irregular astigmatism. J Cataract Refractive Surg. 2003;29:1352-7.

31. Savini G, Hoffer KJ, Carbonelli M, Barboni P. Intraocular lens power calculation after myopic excimer laser surgery: clinical comparison of published methods. J Cataract Refract Surg. 2010;36:1455-65.

32. McCarthy M, Gavanski GM, Paton KE, Holland SP. Intraocular lens power calculations after myopic laser refractive surgery: a comparison of methods in 173 eyes. Ophthalmology. 2011;118:940-4

33. Tang M, Wang L, Koch DD, Li Y, Huang D. Intraocular lens power calculation after previous myopic laser vision correction based on corneal power measured by Fourier-domain optical coherence tomography. J Cataract Refract Surg. 2012;38:589-94

34. Wang L, Booth MA, Koch DD. Comparison of intraocular lens power calculation methods in eyes that have undergone laser-assisted in-situ keratomileusis. Trans Am Ophthalmol Soc. 2004;102:189-96.

35. Hamed AM, Wang L, Misra M, Koch DD. A comparative analysis of five methods of determining corneal refractive power in eyes that have undergone myopic laser in situ keratomileusis. Ophthalmology. 2002;109:651-8.

36. Masket S, Masket SE. Simple regression formula for intraocular lens power adjustment in eyes requiring cataract surgery after excimer laser photoablation. J Cataract Refract Surg. 2006;32:430-4.

37. Chokshi AR, Latkany RA, Speaker MG, Yu G. Intraocular lens calculations after hyperopic refractive surgery. Ophthalmology. 2007;114:2044-9.

38. Diehl JW, Yu F, Olson MD, Moral JN, Miller KM. Intraocular lens power adjustment nomogram after laser in situ keratomileusis. J Cataract Refract Surg. 2009;35:1587-90.

39. Date RC, Yu F, Miller KM. Confirmation and refinement of the Diehl-Miller nomogram for intraocular lens power calculation after laser in situ keratomileusis. J Cataract Refract Surg. 2013;39:745-51.

40. Khalil M, Chokshi A, Latkany R, Speaker MG, Yu G. Prospective evaluation of intraocular lens calculation after myopic refractive surgery. J Refract Surg. 2008;24:33-8.

41. Latkany RA, Chokshi AR, Speaker MG, Abramson J, Soloway BD, Yu G. Intraocular lens calculations after refractive surgery. J Cataract Refract Surg. 2005;31:562-70.

42. Walter KA, Gagnon MR, Hoopes Jr PC, Dickinson PJ. Accurate intraocular lens power calculation after myopic laser in situ keratomileusis, bypassing corneal power. J Cataract Refract Surg. 2006;32:425-9.

43. Zeh WG, Koch DD. Comparison of contact lens overrefraction and standard keratometry for measuring corneal curvature in eyes with lenticular opacity. J Cataract Refract Surg. 1999;25:898-903.
44. Shammas HJ, Shammas MC, Garabet A, Kim JH, Shammas A, LaBree L. Correcting the corneal power measurements for intraocular lens power calculations after myopic laser in situ keratomileusis. Am J Ophthalmol. 2003:136:426-32.

45. Wang $L$, Booth MA, Koch DD. Comparison of intraocular lens power calculation methods in eyes that have undergone LASIK. Ophthalmology. 2004;111:1825-31.

46. lanchulev T, Hoffer KJ, Yoo SH, Chang DF, Breen M, Padrick T, et al. Intraoperative refractive biometry for predicting intraocular lens power calculation after prior myopic refractive surgery. Ophthalmology. 2014;121:56-60

47. Kim JH, Lee D, Joo CK. Measuring corneal power for intraocular lens power calculation after refractive surgery. Comparison Methods. J Cataract Refract Surg. 2002;28:1932-8

48. Mackool RJ, Ko W, Mackool R. Intraocular lens power calculation after laser in situ keratomileusis: Aphakic refraction technique. J Cataract Refract Surg. 2006:32:435-7.

49. Leccisotti A. Intraocular lens calculation by intraoperative autorefraction in myopic eyes. Graefes Arch Clin Exp Ophthalmol. 2008;246:729-33.

50. lanchulev T, Salz J, Hoffer K, Albini T, Hsu H, Labree L. Intraoperative optical refractive biometry for intraocular lens power estimation without axial length and keratometry measurements. J Cataract Refract Surg. 2005;31:1530-6.

51. Sheppard AL, Dunne MC, Wolffsohn JS, Davies LN. Theoretical evaluation of the cataract extraction-refraction-implantation techniques for intraocular lens power calculation. Ophthalmic Physiol Opt. 2008;28:568-76.

52. Canto AP, Chhadva P, Cabot F, Galor A, Yoo SH, Vaddavalli PK, et al. Comparison of IOL power calculation methods and intraoperative wavefront aberrometer in eyes after refractive surgery. J Refract Surg. 2013;29:484-9.

53. Savini G, Bedei A, Barboni P, Ducoli P, Hoffer KJ. Intraocular lens power calculation by Ray-Tracing after myopic excimer laser surgery. Am J Ophthalmol. 2014;157:150-3.

54. Hoffmann P, Wahl J, Preussner PR. Accuracy of intraocular lens calculation with ray tracing. J Refract Surg. 2012;28:650-5.

55. Savini G, Barboni P, Profazio V, Zanini M, Hoffer KJ. Corneal power measurements with the Pentacam Scheimpflug camera after myopic excimer laser surgery. J Cataract Refract Surg. 2008;34:809-13.

56. Saiki M, Negishi K, Kato N, Arai H, Toda I, Torii H, et al. A new centralperipheral corneal curvature method for intraocular lens power calculation after excimer laser refractive surgery. Acta Ophthalmol. 2013;91:e133-9.

57. Ho JD, Liou SW, Tsai RJ, Tsai CY. Estimation of the effective lens position using a rotating Scheimpflug camera. J Cataract Refract Surg. 2008;34:2119-27.

58. Gale RP, Saldana M, Johnston RL, Zuberbuhler B, McKibbin M. Benchmark standards for refractive outcomes after NHS cataract surgery. Eye. 2009;23:149-52.

59. $\mathrm{Hu} Y \mathrm{Y}$, Ye XY, Zhou XL, Li Y, Xu CH, Tian LL, et al. Practical method to calculate post-LASIK corneal power: the Actual K $(a+p)$ method. Int J Ophthalmol. 2010;3:337-41.

60. Geggel HS. Intraocular lens power adjustment after myopic excimer laser surgery: validation studies for Geggel ratio and consensus group. Cornea. 2013;32:1009-14.

61. Awwad ST, Kelley PS, Bowman RW, Cavanagh HD, McCulley JP. Corneal refractive power estimation and intraocular lens calculation after hyperopic LASIK. Ophthalmology. 2009;116:393-400.

62. Awwad ST, Manasseh C, Bowman RW, Cavanagh HD, Verity S, Mootha V, et al. Intraocular lens power calculation after myopic laser in situ keratomileusis: Estimating the corneal refractive power. J Cataract Refract Surg. 2008;34:1070-6.

63. Randleman JB, Foster JB, Loupe DN, Song CD, Stulting RD. Intraocular lens power calculations after refractive surgery: consensus-K technique. J Cataract Refract Surg. 2007;33:1892-8.

64. Feiz V, Mannis MJ, Garcia-Ferrer F, Kandavel G, Darlington JK, Kim E, et al. Intraocular lens power calculation after laser in situ keratomileusis for myopia and hyperopia: a standardized approach. Cornea. 2001;20:792-7.

65. Canovas C, Abenza S, Alcon E, Villegas EA, Marin JM, Artal P. Effect of corneal aberrations on intraocular lens power calculations. J Cataract Refract Surg. 2012;38:1325-32

66. Asia-Pacific Association of Cataract and Refractive Surgeons (APACRS): http://www.apacrs.org

67. Ferrara G, Cennamo G, Marotta G, Loffredo E. New formula to calculate corneal power after refractive surgery. J Refract Surg. 2004;20:465-71. 
68. Haigis W. Intraocular lens calculation after refractive surgery for myopia: Haigis-L formula. J Cataract Refract Surg. 2008;34:1658-63.

69. Hoffer KJ. Intraocular lens power calculation for eyes after refractive keratotomy. J Refract Surg. 1995;11:490-3.

70. Hill W, Wang L, Koch DD. IOL power calculation in eyes that have undergone LASIK/PRK/RK. http://iolcalc.org.

71. Hill WE. IOL power calculations following keratorefractive surgery. presented at Cornea Day of the ASCRS Symposium on Cataract, IOL and Refractive Surgery. San Francisco, California; March, 2006.

72. Rosa N, Capasso L, Lanza M. IOL calculations after refractive surgery. J Cataract Refract Surg. 2006;32:1984. author reply 1984-5.

73. Stakheev A, Balashevich LJ. Corneal power determination after previous corneal refractive surgery for intraocular lens calculation. Cornea. 2003;22:214-20.

74. Saiki M, Negishi K, Kato N, Torii H, Dogru M, Tsubota K. Ray tracing software for intraocular lens power calculation after corneal excimer laser surgery. Jpn J Ophthalmol. 2014;58:276-81.

75. Razmjoo H, Peyman A, Kashfi A, Peyman M, Dehghani A. A regression model for correcting intraocular lens power after refractive surgery independent of preoperative data. Eur J Ophthalmol. 2006;16:525-9.

76. Ronje L. Avoid IOL, surprises in refractive patients. EyeNet American Acad Ophthalmology. 2004;8:23-4.

77. Saiki M, Negishi K, Kato N, Ogino R, Arai H, Toda I, et al. Modified double-K method for intraocular lens power calculation after excimer laser corneal refractive surgery. J Cataract Refract Surg. 2013;39:556-62.

78. Savini G, Barboni P, Zanini M. Intraocular lens power calculation after myopic refractive surgery: theoretical comparison of different methods. Ophthalmology. 2006;113:1271-82.

79. Arce CG, Soriano ES, Weisenthal RW, Hamilton SM, Rocha KM, Alzamora JB, et al. Calculation of intraocular lens power using Orbscan II quantitative area topography after corneal refractive surgery. J Refract Surg. 2009;25:1061-74.

80. Qazi MA, Cua IY, Roberts CJ, Pepose JS. Determining corneal power using Orbscan II videokeratography for intraocular lens calculation after excimer laser surgery for myopia. J Cataract Refract Surg. 2007;33(1):21-30.

81. Shammas HJ, Shammas MC. No-history method of intraocular lens power calculation for cataract surgery after myopic laser in situ keratomileusis. J Cataract Refract Surg. 2007;33(1):31-6.

82. Javadi MA, Feizi S, Malekifar P. Intraocular lens power calculation after corneal refractive surgery. J Ophthalmic Vis Res. 2012;7(1):10-6.

83. Cai JQ, Zhang JY, Chen R, Yang SH, Zha Y, Shi MG. [Orbscan II-assisted intraocular lens power calculation after LASIK]. Zhonghua Yi Xue Za Zhi. 2011;91(1):33-6

\section{Submit your next manuscript to BioMed Central and take full advantage of:}

- Convenient online submission

- Thorough peer review

- No space constraints or color figure charges

- Immediate publication on acceptance

- Inclusion in PubMed, CAS, Scopus and Google Scholar

- Research which is freely available for redistribution 